\title{
STOCHASTIC ANALYSIS TO ASSESS THE PERFORMANCE OF PELTON WHEEL TEST RIG KEEPING SPEED CONSTANT
}

\author{
Pranav Kulkarni ${ }^{1}$, Vaibhavi Naik ${ }^{2}$, Neena Panandikar ${ }^{3}$
}

\begin{abstract}
Hydraulic Turbines are being used since the ancient times to harness the energy stored in flowing streams, rivers and lakes. The oldest and the simplest form of a hydraulic turbine was the waterwheel used for grinding grains. The basic idea of a Pelton Wheel Turbine is derived from this ancient waterwheel.
\end{abstract}

Pelton wheel is the only hydraulic turbine of the impulse type in common use. It is named after the American engineer Laster A. Pelton, who contributed much to its development around the year 1880. Therefore, this machine is known as Pelton Turbine or Pelton Wheel. Pelton Wheels are the preferred turbine for hydro-power when the available water source has relatively high hydraulic head at low flow rates.

In the present study, a complete analysis of the Pelton Wheel Test Rig with brake drum loading made available on college campus is carried out. The major input and output parameters along with their working ranges are identified. Stochastic analysis using Monte Carlo's simulation is carried out by randomly generating a design matrix and thus calculating the responses using predetermined equations. Response Surface Methodology is adapted to identify the optimal set of inputs and also generate inputoutput relations.

Furthermore, a design matrix is generated by taking practical readings on the Test Rig keeping speed constant and the respective outputs are calculated. Similar to the stochastic study, Response Surface Methodology is adapted by inputting the design matrix in a design expert software. Input-output relations are generated and also the optimal set of input parameters are determined using this software.

Keywords: Stochastic analysis, Monte Carlo's simulation, Response Surface Methodology $* * *$

\section{INTRODUCTION}

Hydraulic Turbines have a row of blades fitted to the rotating shaft or a rotating plate. Flowing liquid, mostly water, when passedthrough the hydraulic turbine strikes the blades of the turbine and makes the shaft rotate. While flowing through the hydraulic turbine the velocity and pressure of the liquid reduces, resulting in the development of torque hence rotating the turbine shaft. There are different forms of hydraulic turbines in use depending on the operational requirements. For every specific use, a particular type of hydraulic turbine provides the optimum output.

The basic components of a Pelton Turbine include reservoir, penstock, check valve, nozzle, spear, rotating wheel (runner) with buckets/vanes, casing and output shaft as shown in Figure 1.

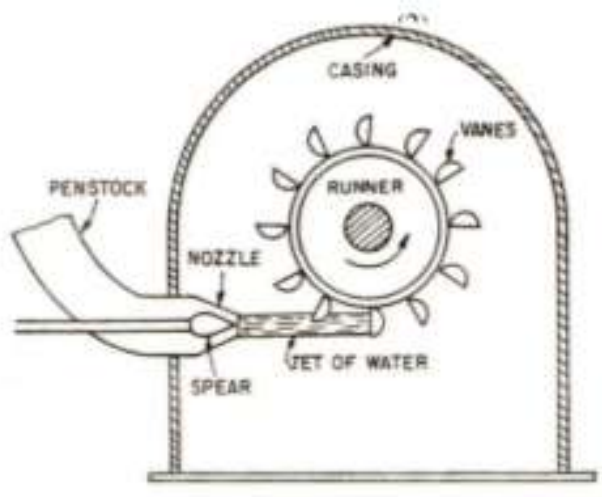

Fig 1: Components of a Pelton Turbine.

The basic working principle of Pelton Turbine is simple: when a high speed water jet injected through a nozzle hits the buckets of Pelton Wheel it induces an impulsive force. This force makes the turbine rotate. The rotating shaft runs a generator and produces electricity.

Nozzles direct forceful, high-speed streams of water against a rotary series of spoon-shaped buckets, also known as impulse blades, which are mounted around the circumferential rim of a drive wheel, also called a runner. As the water jet hits the contoured bucket-blades, the direction of water velocity is changed to follow the contours of the 
bucket. Water impulse energy exerts torque on the bucketwheel system thus spinning the wheel. The water stream itself does a "U-turn" and exits at the outer sides of the bucket. While doing so it decelerates to a lower velocity. In the process, the water jet's momentum is transferred to the wheel and thence to the turbine. A very small percentage of the water jet's original kinetic energy remains in the water. This helps the bucket to be emptied at the same rate it is filled, and thereby allows the high-pressure input flow to continue uninterrupted, without wastage of energy. Typically, two buckets are mounted side-by-side on the wheel, which splits the water jet into two equal streams. This balances the side-load forces on the wheel and helps to ensure smooth, efficient transfer of momentum of the fluid jet of water to the turbine wheel. ${ }^{[1]}$

In this project we aim to generate response equations in terms of input variables and find the optimal set of input parameters using Response Surface Methodology (RSM) for constant speed readings. Furthermore, the optimal set of inputs are tested on the Test Rig available and respective responses arecalculated using pre-determined equations and compared with the values obtained through RSM. Thus the error is determined. Response Surface methodology is carried out using Design Expert 10 software by stat-ease.

\section{MATERIALS AND METHODS}

The Pelton Turbine used is a laboratory test rig designed and fabricated for engineering graduate and post graduate student's laboratory experimental purpose. Some of the aspects of the turbine used in the present investigation are described below:

The Pelton turbine used in the present investigation is similar to the conventional turbine which consists of three basic components: a stationary inlet nozzle, a runner and a casing. The runner consists of multiple buckets mounted on a rotating wheel. The inlet nozzle jet strikes the buckets and imparts momentum. The buckets are shaped in a manner to divide the flow in half and turn its relative velocity vector by nearly $180^{\circ}$. The turbine experimental facility supplied is fitted with a centrifugal pump set, a brake drum and belt system, a spring balance, a tachometer, pressure valves, a sump tank and a nozzle arranged in such a way such that the whole unit functions as a re-circulating water system. The centrifugal pump set supplies the water from sump tank to the turbine through control valve. ${ }^{[2]}$ The loading of the turbine is achieved by brake drum connected to spring balance. A V-notch arrangement is used to find the discharge of this system. Specifications of the Pelton Wheel Test Rig are provided below in Table 1.

Table 1: Specifications of the Pelton Wheel Turbine.

\begin{tabular}{|l|l|}
\hline $\begin{array}{l}\text { Supply pump } \\
\text { Specifications }\end{array}$ & $\begin{array}{l}50 \mathrm{~Hz}, \mathrm{AC}, 440 \mathrm{~V}, \\
7.5 \mathrm{hp}, 3 \mathrm{ph}\end{array}$ \\
\hline Turbine Mean Diameter & $259 \mathrm{~mm}$ \\
\hline Number of buckets & 20 \\
\hline Diameter of Jet & $18 \mathrm{~mm}$ \\
\hline Head & $100 \mathrm{~m}$ \\
\hline
\end{tabular}

\begin{tabular}{|l|l|}
\hline Loading & Brake drums \\
\hline Maximum shaft output & $1.5 \mathrm{~kW}, \quad \mathrm{~V}-$ \\
& notch $=60^{\circ}, \mathrm{C}_{\mathrm{d}}=0.6$ \\
\hline
\end{tabular}

\section{Determining Turbine Parameters}

The first step involves finding the major input and output parameters of the Pelton Wheel Turbine. Parameters are widely divided into three categories:

1. Design Parameters

2. Input Parameters

3. Output Parameters

In this study we do notconsider the design parameters such as number of buckets, diameter of jet, diameter of runner and other such parameters.

By understanding the past studies and the working of Pelton Wheel the following major input and output parameters are identified and listed in Table 2. ${ }^{[4]}$

Table 2: Input and Output Parameters

\begin{tabular}{|l|l|}
\hline Input Parameters & Output Parameters \\
\hline head over notch $(\mathrm{h}$ in $\mathrm{cm})$ & Discharge $\left(\mathrm{Q}\right.$ in $\left.\mathrm{m}^{3} / \mathrm{s}\right)$ \\
\hline Pressure $\left(\mathrm{P}\right.$ in $\left.\mathrm{kg} / \mathrm{cm}^{2}\right)$ & $\begin{array}{l}\text { Hydraulic Pressure } \\
\left(\mathrm{P}_{\text {hyd }} \text { in } \mathrm{kW}\right)\end{array}$ \\
\hline $\begin{array}{l}\text { Speed of Runner(N in } \\
\mathrm{rpm})\end{array}$ & $\begin{array}{l}\text { Brake Power(BP in } \\
\mathrm{kW})\end{array}$ \\
\hline Load(F in $\mathrm{kgf})$ & Efficiency $(\eta$ in \%) \\
\hline
\end{tabular}

The head over the V-notch is measured using a metric scale attached along the $\mathrm{V}$-notch which is then used to calculate the discharge using the pre-determined equation. Pressure in the pipeline is measure using the pressure valve and indicated on a pressure dial. Speed of runner is measured using the tachometer and is indicated on a digital display. Loading is done using the brake drum system with a spring balance used to measure the loading and indicated on an analogue display.

\section{Pre-Determined Input-Output Relations}

The output responses are calculated using pre-determined theoretical equations. These equations are obtained from reference sources and are shown below. ${ }^{[3]}$

1. Head on turbine ( $H$ in $m$ of water $)=10 \times P$

2. Discharge $\left(Q\right.$ in $\left.\mathrm{m}^{3} / \mathrm{s}\right)=\frac{8}{15} C_{d} \tan (\theta / 2) h^{5 / 2}$

3. Hydraulic Pressure $\left(P_{\text {hyd }}\right.$ in $\left.K w\right)=\frac{Q \rho g H}{1000}$

4. Brake Power $(B P$ in $k W)=\frac{2 \pi N F r g}{60 \times 1000}$

5. Turbine efficiency $(\eta$ in $\%)=\left(B P / P_{\text {hyd }}\right) \times 100$

Where,

$\Theta$ is the degree of notch $=60^{\circ}$

$\mathrm{g}$ is acceleration due to gravity $=9.81 \mathrm{~m}^{2} / \mathrm{s}$

$\mathrm{C}_{\mathrm{d}}$ is the coefficient of discharge $=0.6$

$\mathrm{P}$ is the density of water $=1000 \mathrm{~kg} / \mathrm{m}^{3}$

$\mathrm{r}$ is the radius of brake drum $=0.15 \mathrm{~m}$ 


\section{Determining Limits of Input Variables}

The analytical procedure first requires to identify and specify the domain in which the experiment is to be conducted, that is, the limits of the input parameters. These are decided based on previous historical data and the specifications of the Test Rig. A lower limit and upper limit are established for each of the input variables. The values are then varied within these limits to generate respective responses. Thus the following limits were considered based on turbine specifications and historic data:

head over notch (h) varies from 8 to $13 \mathrm{~cm}$

Speed (N) of runner varies from 700 to $1200 \mathrm{rpm}$

Load $(\mathrm{F})$ on the output shaft varies from 0.1 to $9 \mathrm{kgf}$

Inlet pressure $(\mathrm{P})$ varies from 1 to $5 \mathrm{~kg} / \mathrm{cm}^{2}$

\section{Stochastic Analysis}

A stochastic systemis one that is unpredictable due to the influence of a random variable. Researchers refer to physical systems in which they are uncertain about the values of parameters, measurements, expected input and disturbances as stochastic systems. In probability theory, a purely stochastic system is one whose state is randomly determined, having a random probability distribution or pattern that may be analysed statistically but may not be predicted precisely. In this regard, it can be classified as non-deterministic so that the subsequent state of the system is determined probabilistically. ${ }^{[1]}$

Thus, we use stochastic approach to generate a design matrix of random input values and its respective responses to take into consideration uncertainties which may be caused due to vibration, friction and other such factors. Thousand readings of randomly generated input values are taken and respective responses are generated. This is done by MonteCarlo's simulation using excel sheet.

\section{Monte Carlo's Simulation using Excel}

Monte Carlo method is a broad class of computational algorithms that rely on repeated random sampling to obtain numerical results. Their essential idea is using randomness to solve problems that might be deterministic in principle. It shows the extreme possibilities as well as all middle order consequences. Monte Carlo simulation performs risk analysis by building models of possible results by substituting a probability distribution for any factor that has inherent uncertainty. It then calculates results over and over, each time using a different set of random values from the probability functions. Depending upon the number of uncertainties and the ranges specified for them, a Monte Carlo simulation could involve thousands or tens of thousands of recalculations before it is complete. Monte Carlo simulation produces distributions of possible outcome values. ${ }^{[1]}$

Monte Carlo methods vary, but tend to follow a particular pattern:

1. Define a domain of possible inputs.

2. Generate inputs randomly from a probability distribution over the domain.
3. Perform a deterministic computation on the inputs.

4. Aggregate the results.

This was done using Excel sheet with a thousand iterations by randomizing all the input variables. The limits of input parameters are already determined. These are then randomly generated in excel using the below formula:

RAND ()$*($ Difference between limits $)+($ Lower limit $)$

The respective responses are then generated using the predetermined formulas mentioned earlier and the graphs of response distributions are shown in Graphs 1-4.
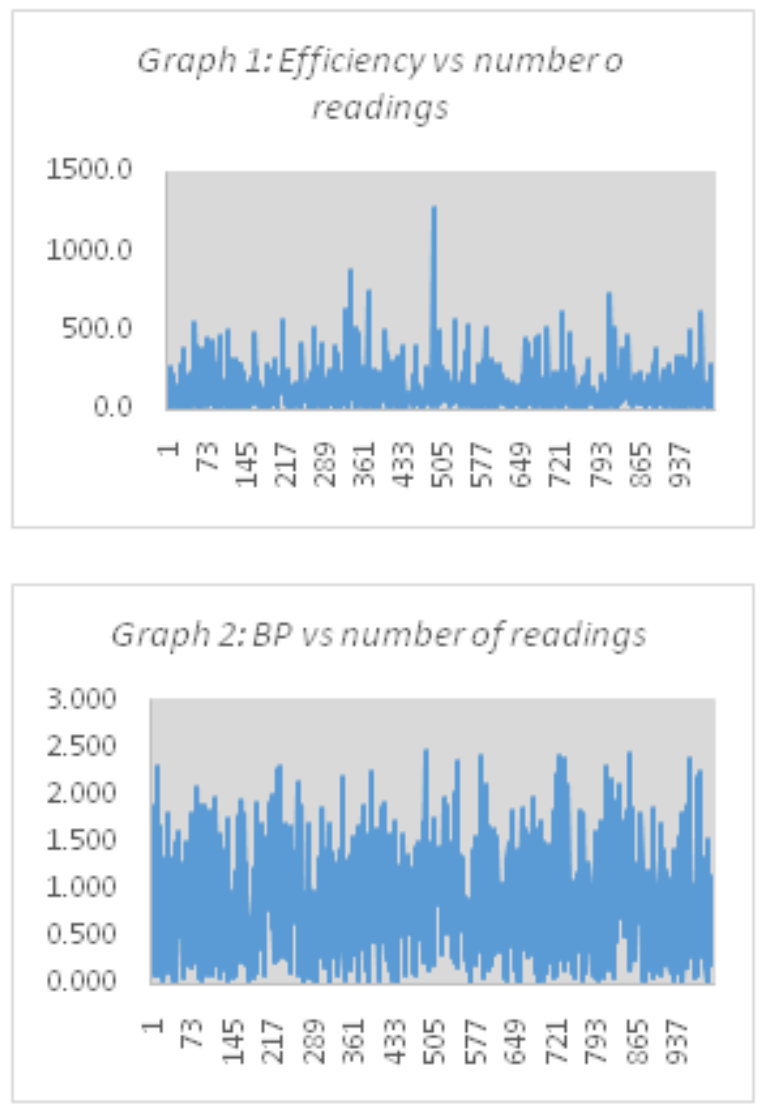

Graph 3: $P_{\text {hyd }}$ vs number of readings

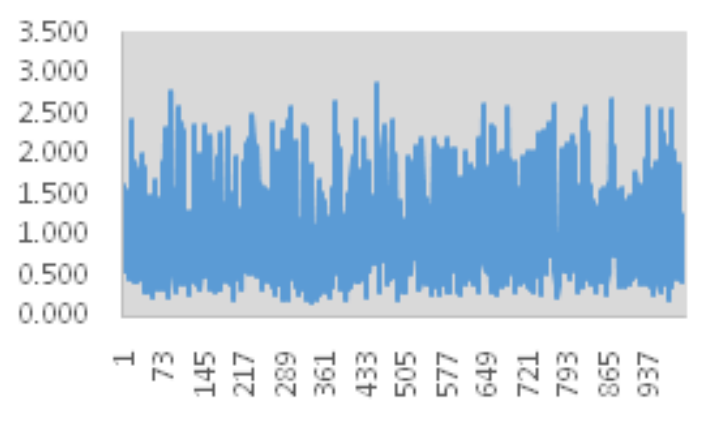




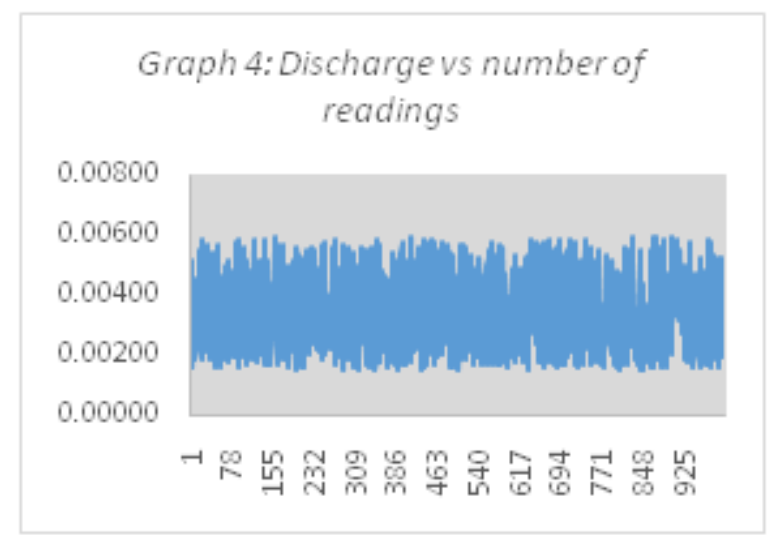

From these graphs we can see the responses calculated by randomized input values. Notice in Graph 4, Discharge is within a certain band as it is only function of head over notch. Thus it is in a bandwidth of a certain constant multiplied to the bandwidth of head over notch.

\section{Response Surface Methodology (RSM)- using \\ Design Expert Software}

Response Surface Methodology is a collection of mathematical and statistical techniques for empirical model building. The objective is to optimize a response which is influenced by several independent input variables.

Thus in this study we use RSM to generate response equations in terms of input parameters and also to find the optimal set of inputs to get an optimal output. This procedure is conducted for stochastic as well as Test Rig design matrices using Design Expert 10 software by stat ease.The 3-D graphs generated for the ouputs using Response Surface Methodology through Design Expert software for the stochastic design matrix are shown in Figures2-6.

\section{Design Matrix from Test Rig}

Experiments are conducted on the Pelton Wheel Test Rig keeping speed constant. Twenty-six readings in five sets are taken using constant speed in the range 700 to 1200 . The readings are shown in Table 3.

\section{Design of Experiment Procedure}

1. Designing of experiments for adequate and reliable measurement of the response.

2. Developing a mathematical model of the second-order response surface with the best fittings.

3. Finding the optimal set of parameters that produce a maximum or minimum value of response.

4. Representing the direct and interactive effects of process parameters through two or three dimensional plots.

If all controlled variables are assumed to be measurable then the response surface can be expressed as: where ' $y$ ' is the output and ' $\mathrm{x}_{\mathrm{i}}$ ' are the input variables called factors, where $\mathrm{i}=1,2 \ldots \mathrm{k}$.

The goal in this aspect of the study is to optimize the response variable ' $y$ '. The independent variables are assumed to be continuous and controllable by the experiments with negligible errors. A reasonable approximation for the true functional relationship between independent variables and the response surface is desired. Different models can be used in RSM as per the fit of the model example: linear, quadratic, cubic, 2FI and other such models. ${ }^{[3]}$

\section{RESULTS}

Test Rig readings of Pelton Wheel Turbine for different values of constant speed are shown in Table 3. As expected, from the table we can infer that to maintain constant speed as the Load is increased the Pressure too needs to be increased. Thus, Pressure is directly proportional to Load, considering Speed is constant. Also, it can be noticed that the Efficiency of the turbine increases with the increase in Load up to a certain limit after which it starts declining.

The 3-D plots of the responses generated using Design Expert Software are shown in Figures 7-11. The inputoutput relations are also generated by using Response Surface Methodology which help us to calculate the outputs directly by knowing the input values.

\section{Relation between Head and Input Parameters}

It is seen that a Head fits a linear model with the input parameters as shown in the equation below:

$$
\begin{array}{r}
\mathrm{H}=(1.730 * \mathrm{E}-014)+(2.285 * \mathrm{E}-017 * \mathrm{~N})+(10 * \mathrm{P}) \\
+(1.918 * \mathrm{E}-015 * \mathrm{~F})-(3.751 * \mathrm{E}-013 * \mathrm{~h})
\end{array}
$$

\section{Relation between Discharge and Input Parameters}

Discharge fits a quadratic model with the input parameters which is shown in equation below:

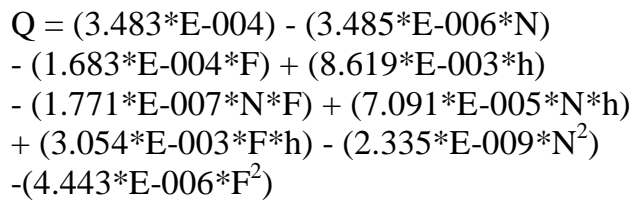

\section{Relation between Hydraulic Pressure and Input Parameters}

Hydraulic Pressure fits a 2FI model with the input parameters which is further modified to get the equation below:

$$
\begin{aligned}
& \mathrm{P}_{\mathrm{hyd}}=(1.949)-(1.940 * \mathrm{E}-003 * \mathrm{~N})-(0.513 * \mathrm{P}) \\
& -(0.066 * \mathrm{~F})-(19.005 * \mathrm{~h})-(1.882 * \mathrm{E}-004 * \mathrm{~N} * \mathrm{P}) \\
& +(7.276 * \mathrm{E}-005 * \mathrm{~N} * \mathrm{~F})+(0.0191 * \mathrm{~N} * \mathrm{~h}) \\
& +(9.072 * \mathrm{P} * \mathrm{~h})
\end{aligned}
$$

$$
y=f\left(x_{1}, x_{2}, x_{3} \ldots \ldots x_{k}\right)
$$




\section{Relation between Brake Power and Input}

\section{Parameters}

Brake power has a large maximum to minimum ratio thus a logarithmic transformation is appliedproviding a 2FI model fit with the input parameters as shown in the equation below:

$\log _{10}(\mathrm{BP})=-(1.860)+(0.201 * \mathrm{P})+(0.535 * \mathrm{~F})$

$-(0.083 * \mathrm{P} * \mathrm{~F})$

\section{Relation between Efficiency and Input Parameters}

Efficiency also has a large maximum to minimum ratio thus a logarithmic transformation is applied provided a $2 \mathrm{FI}$ model fit with the input parameters as shown in the equation below:

$\log _{10}(\eta)=(2.012)+(9.077 * \mathrm{E} 004 * \mathrm{~N})+(0.013 * \mathrm{P})$

$+(0.517 * \mathrm{~F})-(18.935 * \mathrm{~h})-(0.0713 * \mathrm{P} * \mathrm{~F})$

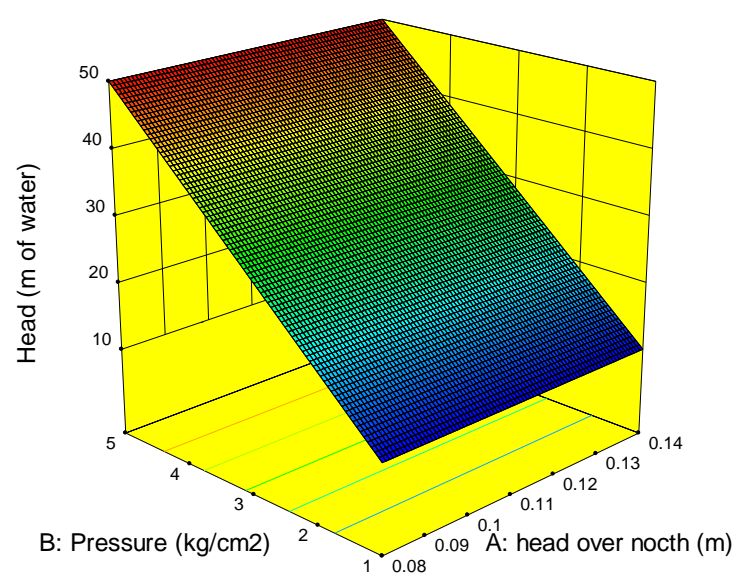

Fig 2: Shows variation of Head against Pressure and head over notch

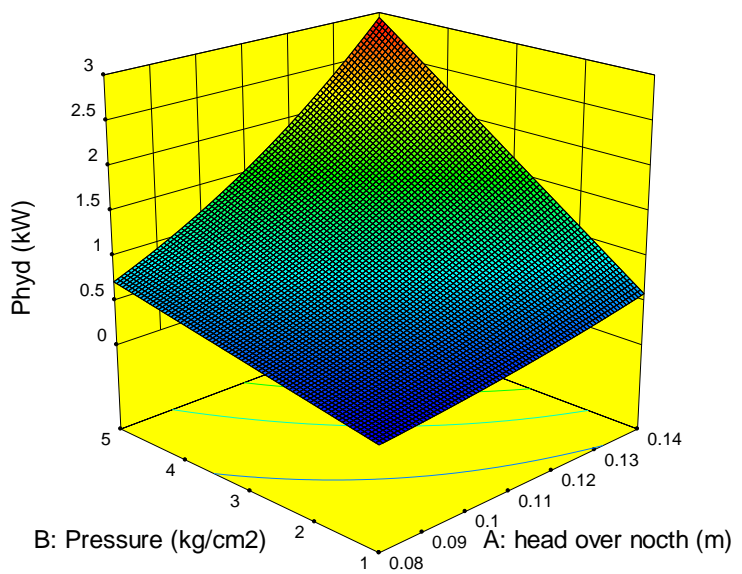

Fig 3: Shows variation of $P_{\text {hyd }}$ against Pressure and head over notch

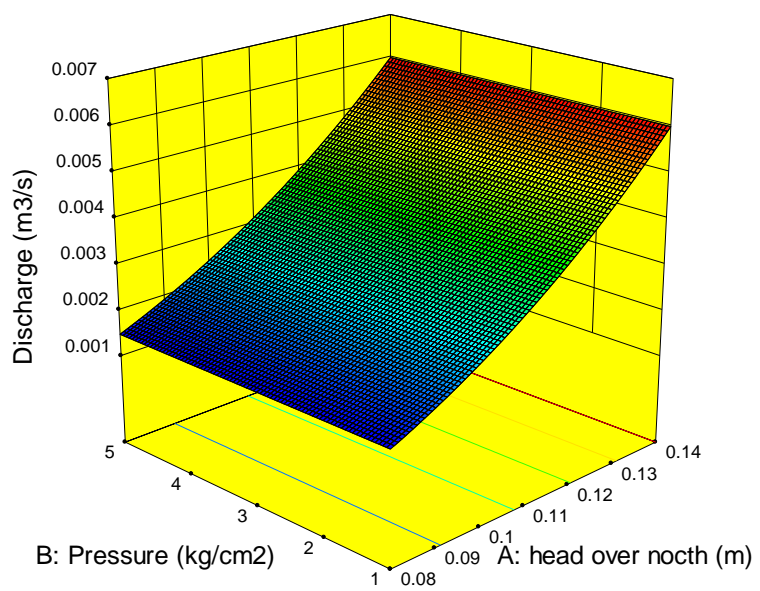

Fig 4: shows variation of Discharge against Pressure and head over notch

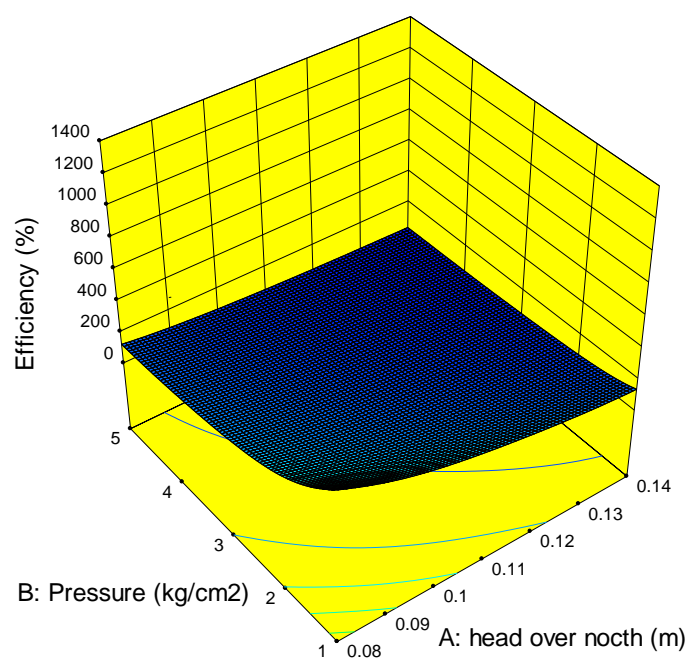

Fig 5: Shows variation off Efficiency against Pressure and head over notch

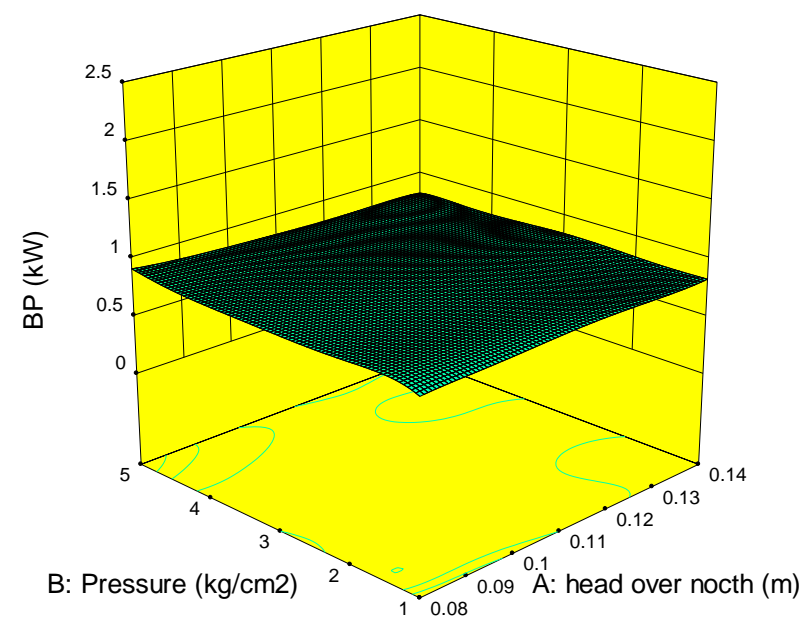

Fig 6: Shows variation of BP against Pressure and head over notch 
Table 3: Test rig readings for constant speed

\begin{tabular}{|c|c|c|c|c|c|c|c|c|}
\hline \multicolumn{4}{|c|}{ INPUTS } & \multicolumn{5}{|c|}{ OUPUT PARAMETERS } \\
\hline $\begin{array}{l}\text { Speed } \\
(\mathrm{rpm})\end{array}$ & $\begin{array}{l}\text { Pressure } \\
\left(\mathrm{kg} / \mathrm{cm}^{2}\right)\end{array}$ & $\begin{array}{l}\text { Load } \\
\text { (kgf) }\end{array}$ & $\begin{array}{l}\text { head over } \\
\text { notch }(\mathrm{m})\end{array}$ & $\begin{array}{l}\text { Head (m } \\
\text { of water) }\end{array}$ & $\begin{array}{l}\text { Discharge } \\
\left(\mathrm{m}^{3} / \mathrm{s}\right)\end{array}$ & $\begin{array}{l}\text { Phyd } \\
(\mathrm{kW})\end{array}$ & $\begin{array}{l}\mathrm{BP} \\
(\mathrm{kW})\end{array}$ & $\begin{array}{l}\text { Efficiency } \\
(\%)\end{array}$ \\
\hline 700 & 2.6 & 0.725 & 0.087 & 26 & 0.0018 & 0.4660 & 0.0782 & 16.77 \\
\hline 700 & 3.2 & 1.25 & 0.0919 & 32 & 0.0021 & 0.6577 & 0.1348 & 20.49 \\
\hline 700 & 4 & 1.05 & 0.0932 & 40 & 0.0022 & 0.8515 & 0.1132 & 13.29 \\
\hline 700 & 4.5 & 1.875 & 0.094 & 45 & 0.0022 & 0.9786 & 0.2021 & 20.66 \\
\hline 700 & 5 & 2 & 0.0962 & 50 & 0.0023 & 1.1521 & 0.2156 & 18.72 \\
\hline 800 & 1 & 0.15 & 0.1061 & 10 & 0.0030 & 0.2944 & 0.0185 & 6.28 \\
\hline 800 & 1.8 & 0.9 & 0.1058 & 18 & 0.0030 & 0.5261 & 0.1109 & 21.08 \\
\hline 800 & 2.4 & 2.9 & 0.1058 & 24 & 0.0030 & 0.7015 & 0.3573 & 50.94 \\
\hline 800 & 2.7 & 2 & 0.1066 & 27 & 0.0030 & 0.8042 & 0.2464 & 30.64 \\
\hline 800 & 3.1 & 3.8 & 0.1153 & 31 & 0.0037 & 1.1234 & 0.4682 & 41.68 \\
\hline 800 & 3.8 & 5 & 0.1223 & 38 & 0.0043 & 1.5956 & 0.6161 & 38.61 \\
\hline 800 & 5.4 & 8.5 & 0.126 & 54 & 0.0046 & 2.4429 & 1.0473 & 42.87 \\
\hline 900 & 1.6 & 0.1 & 0.1127 & 16 & 0.0035 & 0.5477 & 0.0139 & 2.53 \\
\hline 900 & 1.8 & 0.7 & 0.1156 & 18 & 0.0037 & 0.6565 & 0.0970 & 14.78 \\
\hline 900 & 2.4 & 2 & 0.1186 & 24 & 0.0040 & 0.9333 & 0.2772 & 29.71 \\
\hline 900 & 2.6 & 2.8 & 0.1205 & 26 & 0.0041 & 1.0520 & 0.3881 & 36.89 \\
\hline 900 & 3.3 & 3.9 & 0.1236 & 33 & 0.0044 & 1.4228 & 0.5406 & 38.00 \\
\hline 1000 & 2 & 0.2 & 0.116 & 20 & 0.0038 & 0.7358 & 0.0308 & 4.19 \\
\hline 1000 & 2.1 & 0.5 & 0.12 & 21 & 0.0041 & 0.8409 & 0.0770 & 9.16 \\
\hline 1000 & 3.2 & 3.45 & 0.132 & 32 & 0.0052 & 1.6262 & 0.5314 & 32.68 \\
\hline 1000 & 3.8 & 5 & 0.135 & 38 & 0.0055 & 2.0427 & 0.7701 & 37.70 \\
\hline 1000 & 4.2 & 5.75 & 0.138 & 42 & 0.0058 & 2.3852 & 0.8856 & 37.13 \\
\hline 1100 & 2.6 & 1.9 & 0.1216 & 26 & 0.0042 & 1.0762 & 0.3219 & 29.91 \\
\hline 1100 & 3.6 & 3.05 & 0.1244 & 36 & 0.0045 & 1.5774 & 0.5167 & 32.76 \\
\hline 1100 & 4.2 & 4.2 & 0.125 & 42 & 0.0045 & 1.8625 & 0.7116 & 38.20 \\
\hline 1100 & 4.6 & 4.75 & 0.126 & 46 & 0.0046 & 2.0810 & 0.8047 & 38.67 \\
\hline
\end{tabular}

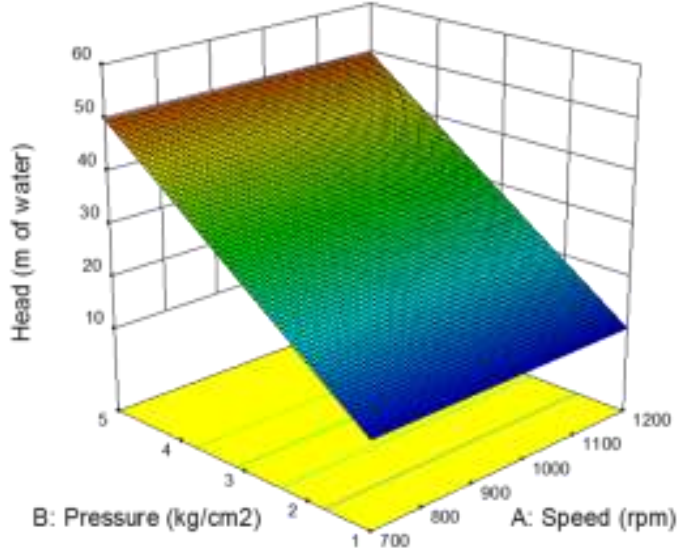

Fig 7: Shows variation of Head against Pressure and Speed

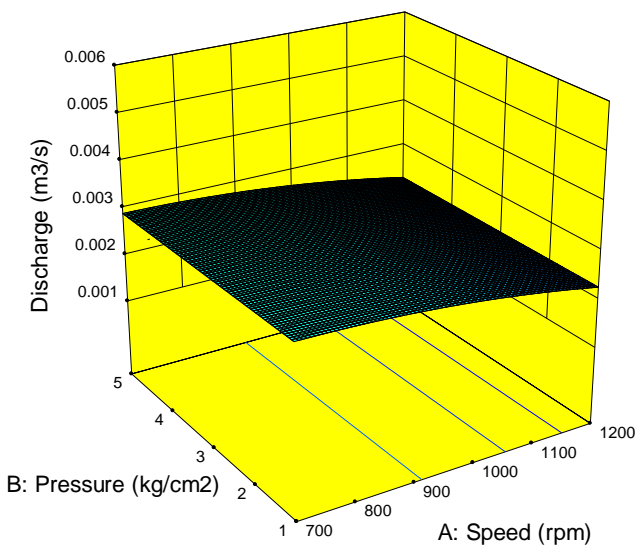

Fig 8: Shows variation of Discharge against Pressure and Speed 


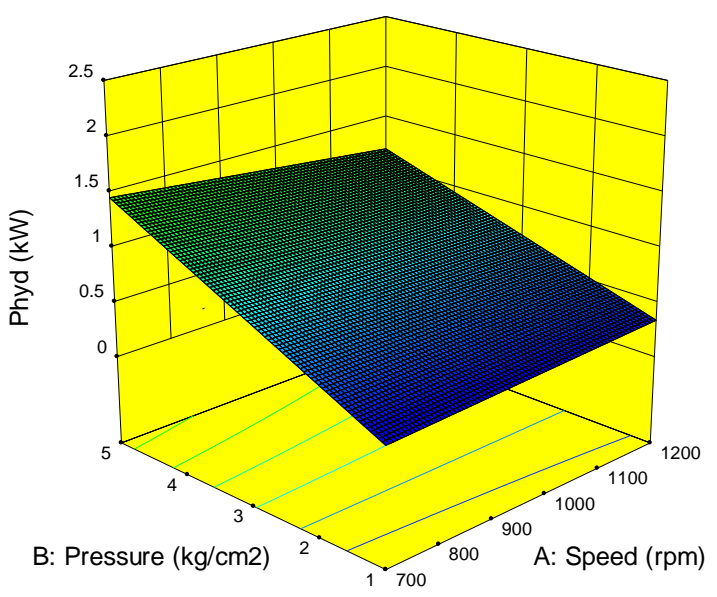

Fig 9: Shows variation of $P_{\text {hyd }}$ against Pressure and Speed

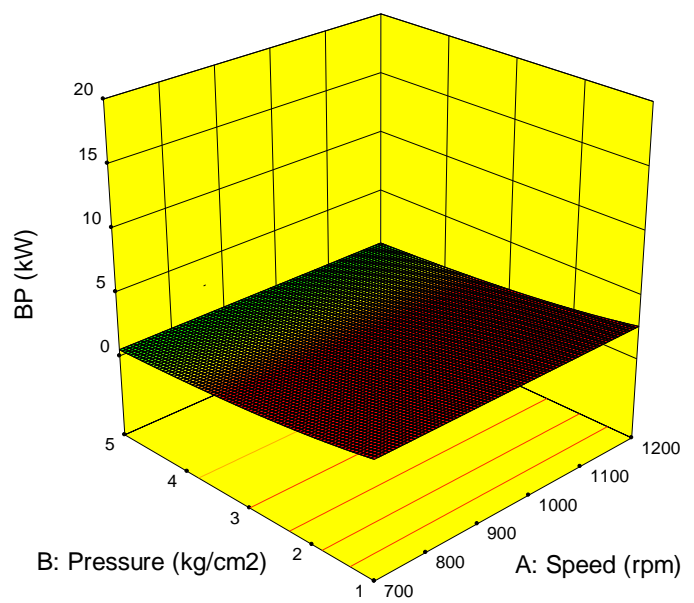

Fig 10: Shows variation of BP against Pressure and Speed

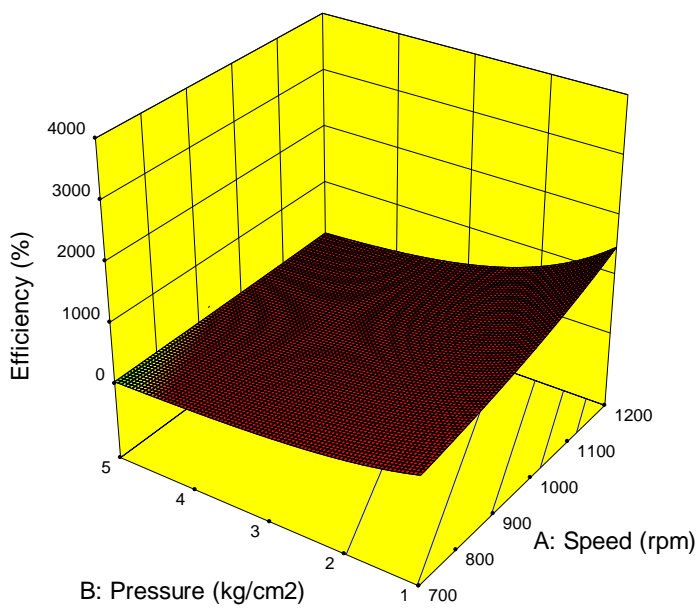

Fig 11: Shows variation of Efficiency against Pressure and Speed

\section{Optimal Solution}

By performing optimization for the test rig design matrix in design expert 10 software it is determined that the optimum efficiency is $\eta=96.96 \%$ with a desirability of 1 .
The respective optimal set of inputs are:

Speed, $\mathrm{N}=1009.74 \mathrm{rpm}$

Pressure, $\mathrm{P}=1.6666 \mathrm{~kg} / \mathrm{cm}^{2}$

Load, $\mathrm{F}=2.102 \mathrm{Kgf}$

head over notch, $\mathrm{h}=0.096 \mathrm{~m}$

The above set of input parameters were experimented on the Test Rig and respective outputs were calculated using the pre-determined equations. The value of Efficiency was found out to be, $\eta=84.86 \%$

\section{CONCLUSION}

Thus, input-output relations were generated and verified. The optimal input set was also identified and the error is calculated,

$$
\text { Error, } \mathrm{e}=96.96-84.86=12.1 \%
$$

This error may be caused due to frictional loses along pipe lengths and bends and other frictional loses.

\section{REFERENCES}

[1]. https://en.wikipedia.org/wiki/Main_Page Wikipedia, the free encyclopaedia, Pelton Wheel, Monte Carlo's Simulation and Water Turbine.

[2]. Turkish Journal of Engineering, Science and Technology, Assessment on the Performance of Pelton Turbine Test Rig Using Response Surface Methodology by Alok Ku Nandaa, Soumya Dashb, R. Bhima Raoc, Satya Sai Srikantd, 2013.

[3]. Kadambi V. Manohar Prasad: An introduction to energy conversion, Volume III, New Age Publications, 1997.

[4]. R K Bansal, (2010), A Textbook of fluid mechanics and hydraulic machines, Laxmi Publications, 9th Edition (2010). 